\title{
Influence of History, Geography, and Economics on the Elimination of Malaria: A Perspective on Disease Persistence in Rural Areas of Zambia
}

\author{
Mukumbuta Nawa $^{1 *}$ \\ ${ }^{1}$ University of Zambia, School of Public Health, Department of Policy and Management, Lusaka, Zambia \\ Corresponding Author: Mukumbuta Nawa, MD, University of Zambia, School of Public Health, Department of Policy and \\ Management, Ridgeway Campus, P.O. Box 50110, Lusaka, Zambia. Tel: +260-977392064, Email: mktnawa@gmail.com
}

Received July 11, 2019; Accepted November 11, 2019; Online Published December 15, 2019

\begin{abstract}
The fight against malaria is currently ongoing in many countries where the disease is still endemic. The overall target is to eliminate malaria in all nations, regardless of their malaria burden, by 2030. Currently, the disease has been eliminated mainly in low-burden and unstable malaria areas globally. However, in high-burden countries, particularly in Africa, the disease is still not eliminated; some countries are even recording increases in incidence. This paper discusses why the disease is currently being eliminated in some countries and not in others using a historical and geo-economic perspective. It identifies gaps in the primary contemporary interventions in high endemic areas, particularly in rural constituencies where incidence of the disease is even higher. The key discussion point is that poor housing and behavioral patterns predispose rural dwellers to more malaria. Other risk factors include agricultural occupations, livestock keeping, and the fact that mosquito vectors in Africa thrive more in rural than urban areas. Combating malaria in rural African areas, therefore, requires radical transformative action to address the unique situations that currently enable the persistence of malaria beyond the contemporary, mainly indoor, and health facility-based interventions. Improving housing structures in rural Africa, which are mainly mud and thatched huts, to at least insect-proof standards is the recommended transformative action. Moreover, behavioral patterns, such as cooking outdoors in the evenings, must be modified to cooking in improvised insect-proof kitchens.

Keywords: Malaria, Elimination, Housing, Structures, Mosquito, Africa
\end{abstract}

Citation: Nawa M. Influence of history, geography, and economics on the elimination of malaria: a perspective on disease persistence in rural areas of Zambia. Int J Travel Med Glob Health. 2019;7(4):113-117. doi:10.15171/ijtmgh.2019.24.

\section{Introduction}

Malaria elimination is not an unachievable pipe dream. ${ }^{1}$ Several countries which were once malaria-endemic have managed to eliminate the disease over time through interventions. ${ }^{2}$ As late as 1945, malaria transmission was almost worldwide, including North and South America, Western Europe, continental Europe, the whole of Africa, and the Asian Pacific Region. ${ }^{3}$ By 2015, the World Health Organization (WHO) reported transmission remaining in only 91 countries and territories located mainly along the equator and in the tropics. ${ }^{2}$ Countries in temperate and subtropical regions have eliminated malaria, but the disease remains concentrated in the tropics. The main measure used by malaria-free countries was spraying widely with dichlorodiphenyl-trichloroethane (DDT). Other activities included prophylaxis using quinine and chloroquine on potential infected populations and treatment of infected cases. ${ }^{4}$

Currently, reports on the global malaria situation and progress on elimination list countries that have eliminated or are on track to eliminate malaria without giving context as to the enablers for those that do so. Readers of such reports and policymakers in countries with a high burden of malaria may not understand why they are not eliminating malaria while others are. This perspective aimed to give a contextual understanding of why countries like South Africa and Egypt are on track to malaria elimination, while countries like Zambia and Uganda are not. It also aimed to help refocus the fight against malaria in high-burden countries. Unique solutions can be employed in the most vulnerable areas, such as rural areas in sub-Saharan Africa (SSA), which bear the highest burden of malaria. However, interventions do not seem to recognize the unique drivers in rural areas.

\section{International Collaboration Under the Global Malaria Elimination Program}

While individual countries were priorly fighting malaria, concerted malaria-elimination efforts were spearheaded by the Global Malaria Elimination Program (GMEP) between

Copyright (C) 2019 The Author(s). This is an open-access article distributed under the terms of the Creative Commons Attribution License (http:// creativecommons.org/licenses/by/4.0), which permits unrestricted use, distribution, and reproduction in any medium, provided the original work is properly cited. 
1955 and 1969. The GMEP was established by a resolution of the World Health Assembly (WHA) and coordinated by the WHO. The GMEP helped eliminate malaria in most developed countries in the 14 years of its existence; ${ }^{5}$ however, that was not the case in Africa, where efforts were limited in three countries as it was not considered feasible to extend the campaign to the rest of the continent. ${ }^{5,6}$

\section{The Question of Geographical Location}

The question of the elimination of malaria in developed countries must not be considered in the light of developed versus developing countries. Malaria was eliminated in countries in temperate and subtropical regions in the 1950s, while it persisted in the tropics. Why it persisted there can be addressed with the examples of two countries within the tropics which almost eliminated the disease during the GMEP. In South America, the GMEP had significant impacts between the 1950s and 1970s. For example, Brazil, a country dissected by the equator, managed to reduce the number of malaria cases from four to five million per year among 45 million Brazilians before the GMEP in the 1940s to below 1\% by $1970 .^{7}$ Following the discontinuation of the GMEP, malaria resurged and increased in Brazil between 1970 and 1990. The country has made steady progress in recent years but still grapples with the disease due to the lack of sustainability of the earlier gains. ${ }^{8}$

Another country with a hot and wet tropical climate that lies near the equator but benefited from the GMEP activities in the 1950s and 60s is Sri Lanka, an island off the southern tip of India. It was once a very malarious country with reports of over three million cases out of a population of about six million in 1934/5. Sri Lanka implemented full coverage of indoor residual spraying (IRS) with DDT and intensified prompt diagnosis and treatment of cases as well as the surveillance and reporting of cases through a well-coordinated system. ${ }^{9}$ By 1963, only 17 cases were reported nationwide; this led to the discontinuation of IRS with DDT. The number of cases increased steadily after that, and by 1969 , over half a million cases were reported with further increases occurring into the 1980s. ${ }^{10,11}$ Since 2000, renewed efforts through integrated vector management, case management, and targeted focal interventions led to a steady decline until Sri Lanka was declared malaria free by the WHO in September 2016. ${ }^{12,13}$ The unique situation of Sri Lanka as an island made it advantageous in that it limited the importation of cases from neighboring countries. Such has led others to propose islands such as Zanzibar, Madagascar, Solomon Islands and Vanuatu as candidates for malaria elimination. ${ }^{5,14,15}$

Given that mosquito vectors proliferate more in hot tropical climates, this discourse presents the argument that, irrespective of the location of a country, malaria elimination is possible when the right tools are used at adequate coverage levels long enough to break transmission cycles. Otherwise, Brazil and Sri Lanka, on the equator but at different longitudes, would not have almost eliminated malaria in their countries during the GMEP, just like the temperate and subtropical countries. It also shows that resurgence is likely if methods of prevention of re-establishment are not put in place.

\section{The Question of Economics}

Other than Sri Lanka which lies near the equator (5-10 degrees north), most other countries that have eliminated malaria lie away from the equator by at least 23 degrees north or south. While countries that still have malaria lie between the Tropics of Capricorn and Cancer, it is sufficient to say that the climate and environment in the tropics favor the breeding of mosquito vectors. ${ }^{16}$ The other reason for the persistence of malaria in the tropics is not only environmental, but also economic factors as demonstrated by near elimination in Brazil and Sri Lanka during the GMEP period. Following its suspension in 1969, developing countries (incidentally located in the tropics) could not sustain the interventions using their national resources, and this resulted in the resurgences and reestablishment of malaria. ${ }^{6,17}$

Countries in Africa that are certified malaria-free are Libya (1980), Morocco (2010), and Tunisia (1979). Two other countries, Egypt and Algeria, have had no recent indigenous malaria cases and are in the process of being declared malariafree. ${ }^{2}$ Incidentally, these are countries in the semi-arid region of Africa. They had regional or focal malaria mainly in the oases and river basins. They also lie in the subtropics along the Tropic of Cancer on the same latitude as other countries which have been declared malaria-free or are about to be declared so, such as Iraq and Uzbekistan. In the southern hemisphere, nations that lie in the subtropics, such as Chile and Uruguay, have also been or are about to be declared malaria-free.

One interpretation of this in the context of the GMEP and what happened after that is that, irrespective of where a country is situated, it is possible to eliminate malaria given the right tools, level of resources, and time to break transmission cycles. Countries with unstable or low endemicity of the disease may, with their country resources, be able to eliminate malaria. This was the case with African countries such as Libya and Morocco, which eliminated malaria in the post GMEP and pre-RBM period. ${ }^{5}$ High-burden malaria countries, however, require substantial and sustained additional investments such as was availed during the GMEP. Without maintaining those resources and focusing on locally appropriate interventions, malaria will resurge as it did in Brazil and Sri Lanka postGMEP. ${ }^{8,9}$ These ideas were echoed by the WHO Executive Director in the 2017 World Malaria Report "The WHO African Region continues to account for about $90 \%$ of malaria cases and deaths worldwide. If we are to get the global malaria response back on track, supporting the most heavily affected countries in this region must be our primary focus."2 Similar sentiments were echoed in the Global Fund to fight AIDS, Tuberculosis and Malaria 2018 Report: "Countries tend to fall into one of two categories: those progressing toward malaria elimination and those with a high burden that are slipping backwards in their response. Nearly all countries in the second category are in Africa."18

The Roll Back Malaria (RBM) initiative is one such international collaborative platform in the post-GMEP period that has been in existence since 1998. In its 20182020 strategic plan, it advocates malaria awareness on the global agenda, regional fights against malaria, and increasing 
malaria financing. During its time, key results include a reduction of $60 \%$ of malaria mortality between 2000 and 2015 and a $75 \%$ reduction in cases in 57 countries. ${ }^{19}$ Another critical global collaboration is the WHO Global Technical Strategy for Malaria Elimination (GTS). Among other specific targets, it aims to reduce the global malaria mortality and incidence by $40 \%$ of the 2015 baseline by 2020 and $90 \%$ by $2030 .{ }^{19}$ The GTS recommends a phased approach of reducing the malaria burden using indoor residual spraying (IRS), insecticide-treated nets (ITNs), and facility case management in high-burden areas. Further, it recommends elimination using mass drug administration, community and facility case management, enhanced vector control, and focal investigations in low-burden areas. ${ }^{19,20}$

This discourse shows that developing countries with high malaria burdens need international collaboration to ensure that they have adequate funding for their malaria fights. For malaria to be eliminated, funding needs to be sustained at high intervention coverage levels over long periods of time. Otherwise, only countries at the tips of the continents that have unstable malaria will eliminate malaria, while world opinion leaders like WHO continue to count 'countries' without giving contexts.

\section{Current Eliminations Mostly on the Fringes of Malaria}

My impression of the progress in the fight against malaria post-GMEP is that other than Sri Lanka, which is an island, countries that have eliminated malaria or have reported zero cases are either in temperate or subtropical areas and are not "hotbeds" of the disease. It is more like the "low hanging fruits" are being picked. In SSA which has at least $90 \%$ of the global burden of malaria morbidity and mortality, it is countries at the tips of the continent that have eliminated or are set to eliminate malaria. Countries such as South Africa, Botswana, and Swaziland in the southern hemisphere and Egypt and Algeria in the northern hemisphere are not highburden malaria countries. Twelve of the thirteen countries said to have even increased their burden of malaria between 2010 and 2015 lie in the middle of Africa and have typical tropical ecological conditions and weak economies.

Similarly, countries at the tips of the South American continent, like Argentina, Chile, Uruguay, and Paraguay in the south and Guatemala, Costa Rica, and Mexico in the north, have eliminated malaria or are tipped to be on track to malaria elimination. High-burden tropical countries like Brazil, Peru, Venezuela, and Colombia, which together account for $70 \%$ of malaria in the Americas, are still grappling with the disease. ${ }^{21}$

\section{High-Burden Countries are not Eliminating the Disease}

As noted in the WHO World Malaria Report 2018, 90\% of the reported 216 million cases of malaria reported in 2016 occurred in Africa, 7\% in Southeast Asia, and 2\% in the Eastern Mediterranean. Fifteen countries had $80 \%$ of all these cases, and all but one (India) were in the middle of SSA. ${ }^{2}$ Zambia was also one of the 13 countries that recorded an increase in their malaria burden despite a global decrease in $2015 .^{22}$
The question, therefore, is why are high-burden countries like Zambia, which are in the middle of Africa and weak economically, not eliminating malaria? In line with the GTS, high-burden areas deploy ITNs, IRS, and prompt treatment of cases to reduce the number of malaria cases before implementing eliminating strategies such as mass drug administration and community surveillance, among others. In 2014, Zambia carried out a nation-wide mass ITN distribution campaign and distributed about 4.8 million ITNs, ${ }^{23}$ carried out another nation-wide ITN mass distribution in 2017, and carries out yearly IRS in targeted areas. ${ }^{24,25}$ Following the 2017 countrywide mass distribution campaign, the prevalence of malaria in children below five years of age was reduced to 9.1\%. ${ }^{26}$ One study in northern Zambia evaluated three years of IRS and found only modest declines in malaria prevalence in targeted households in the rainy season. It did not find declines during the dry season or in the overall area, and it called for a more comprehensive package to effectively reduce malaria in such settings. ${ }^{25}$

In 2015 in Zambia, the odds ratio of a positive malaria slide in urban areas compared to rural areas was 0.23 (0.15-0.37), even after adjusting for age, gender, wealth status, housing structures, IRS, and ITNs. ${ }^{22}$ The coverages of malaria interventions as of 2015 in rural areas versus urban areas were similar; $79 \%$ and $73 \%$ of households had at least one ITN, respectively, $29 \%$ and $28 \%$ of homes were sprayed with IRS, respectively, while the rates of prompt treatment of confirmed malaria cases among under-five children were $36 \%$ and $38 \%$, respectively. ${ }^{27}$ This shows that the coverages of major interventions between rural and urban areas were comparable. Therefore, something else not addressed by current strategies must be driving malaria more in rural areas. Program interventions are mainly looking at the supply side; however, there are other societal and entomological factors in rural areas that perpetuate transmission compared to urban areas.

As of the 2010 census of population and housing in Zambia, $60 \%$ of the people lived in rural areas compared to $40 \%$ in urban areas. ${ }^{28}$ One study suggested that the malaria vectors in Africa, A. Gambiae and Funestus, tend not to breed well in urban areas, so their populations and transmission intensities are greater in rural areas. ${ }^{5}$ Modern housing structures in rural areas among the households surveyed during the Malaria Indicator Survey in 2015 in Zambia were only 8\% compared to $39 \%$ in urban areas. Modern housing had a $60 \%$ protective effect against malaria compared to improvised housing structures like mud and thatched-roof structures, which comprised $92 \%$ of the housing structures in rural areas. ${ }^{22}$ Moreover, behavioral practices like cooking in the evenings are done outside the house in rural areas, while in urban areas, cooking is done indoors. ${ }^{29}$ Thus, rural dwellers are more exposed to bites in their settings and lifestyles. Other factors include engagement in agriculture and the keeping of livestock, which are more prevalent in rural areas and are associated with greater malaria transmission. ${ }^{30}$ Combating malaria comprehensively in rural areas needs to go beyond the push strategies of ITNs, IRS, and the treatment of cases. There is a need to address some structural and behavioral 
factors in rural communities.

\section{Conclusion}

In summary, this perspective article reminds us of the background that malaria was distributed worldwide before 1945. For a country to have eliminated its malaria between 1955 and 1969 during the GMEP, it needed to have been located in the temperate and subtropical regions. If a country is located in the tropics and benefited from the GMEP, it risked having a resurgence unless it had a strong economy to sustain its malaria programs in the intervening years before RBM. Countries located at the tips of the American, African, and Asian continents have had a greater chance of eliminating their malaria during the last 20 years under the RBM initiative. This is because they tend to have unstable, low, or focal disease and current tools in the GTS coupled with funding from international collaborators. Other countries or territories that have higher chances of eliminating malaria during the RBM initiative are isolated islands, like Sri Lanka. If a country is located in the tropics in the middle of the continents of South America or Africa and is weak economically, it is likely to be a high-burden country by its location. The current strategies under the GTS that recommend ITNs, IRS, and facility-based treatment do not adequately address their unique disadvantages, particularly their rural constituencies who bear the most significant burden of malaria. There is a need for discussion beyond the push approach to tackling the disease in these areas. I, therefore, call for interventions, which are currently not in the GTS recommendations, that would address malaria in rural areas in high-burden developing countries in SSA, like Zambia, such as improving housing structures in rural areas to at least insect-proof standards; modifying behavioral lifestyles such as cooking indoors; and determining how to reduce the risk of malaria among communities that are engaged in agriculture and livestock keeping.

\section{Conflict of Interest}

The author declares no conflict of interest.

\section{Ethical Approval}

Not applicable.

\section{Acknowledgments}

The author would like to sincerely thank the staff at University of Zambia School of Public Health and School of Medicine, in particular, Prof. Trevor Kaile, Dr. Selestine Nzala, Dr. Patrick Kaonga, Dr. Gershom Chongwe, and Dr. Doreen Chilolo Sitali for being very supportive during this difficult time.

\section{Funding/Support}

The author did not receive any funding for this work.

\section{References}

1. Campbell CC, Steketee RW. Malaria in Africa can be eliminated. Am J Trop Med Hyg. 2011;85(4):584-585. doi:10.4269/ ajtmh.2011.11-0529.

2. WHO. World Malaria Report. World Health Organization, 2017.
3. Hay SI, Guerra CA, Tatem AJ, Noor AM, Snow RW. The global distribution and population at risk of malaria: past, present, and future. Lancet Infect Dis. 2004;4(6):327-336. doi:10.1016/s14733099(04)01043-6.

4. Nájera JA, González-Silva M, Alonso PL. Some lessons for the future from the Global Malaria Eradication Programme (19551969). PLoS Med. 2011;8(1):e1000412. doi:10.1371/journal. pmed.1000412.

5. Feachem RG, Phillips AA, Hwang J, et al. Shrinking the malaria map: progress and prospects. Lancet. 2010;376(9752):1566-1578. doi:10.1016/s0140-6736(10)61270-6.

6. Majori G. Short history of malaria and its eradication in Italy with short notes on the fight against the infection in the mediterranean basin. Mediterr J Hematol Infect Dis. 2012;4(1):e2012016. doi:10.4084/mjhid.2012.016.

7. Griffing SM, Tauil PL, Udhayakumar V, Silva-Flannery L. A historical perspective on malaria control in Brazil. Mem Inst Oswaldo Cruz. 2015;110(6):701-718.doi:10.1590/0074-02760150041.

8. Ferreira MU, Castro MC. Challenges for malaria elimination in Brazil. Malar J. 2016;15(1):284. doi:10.1186/s12936-016-1335-1.

9. Karunaweera ND, Galappaththy GN, Wirth DF. On the road to eliminate malaria in Sri Lanka: lessons from history, challenges, gaps in knowledge and research needs. Malar J. 2014;13:59. doi:10.1186/1475-2875-13-59.

10. Wijesundera Mde S. Malaria outbreaks in new foci in Sri Lanka. Parasitol Today. 1988;4(5):147-150. doi:10.1016/01694758(88)90193-7.

11. Ratnapala R, Subramaniam K, Yapabandara MG, Fernando WP. Chloroquine resistant Plasmodium falciparum in Sri Lanka. Ceylon Med J. 1984;29(3):135-145.

12. Larson E, Gosling R, Abeyasinghe R. Eliminating malaria: following Sri Lanka's lead. BMJ. 2016;355:i5517. doi:10.1136/bmj.i5517.

13. Simac J, Badar S, Farber J, et al. Malaria elimination in Sri Lanka. J Health Spec. 2017;5(2):60-65. doi:10.4103/jhs.JHS_25_17.

14. Björkman A, Shakely D, Ali AS, et al. From high to low malaria transmission in Zanzibar-challenges and opportunities to achieve elimination. BMC Med. 2019;17(1):14. doi:10.1186/s12916-0181243-z.

15. Malaria on isolated Melanesian islands prior to the initiation of malaria elimination activities. Malar J. 2010;9:218. doi:10.1186/1475-2875-9-218.

16. Kar NP, Kumar A, Singh OP, Carlton JM, Nanda N. A review of malaria transmission dynamics in forest ecosystems. Parasit Vectors. 2014;7:265. doi:10.1186/1756-3305-7-265.

17. Snow RW, Amratia P, Kabaria CW, Noor AM, Marsh K. The changing limits and incidence of malaria in Africa: 1939-2009. Adv Parasitol. 2012;78:169-262. doi:10.1016/b978-0-12-3943033.00010-4.

18. The Global Fund Results Report 2018. https://reliefweb.int/sites/ reliefweb.int/files/resources/corporate_2018resultsreport_report_ en.pdf. Accessed December 23, 2019.

19. Roll Back Malaria Partnership. RBM Partnership Strategic Plan 2018-2020. https://endmalaria.org/sites/default/files/RBM-Strategic-Plan-digital-JW-220218.pdf. Accessed December 23, 2019.

20. Ministry of Health. National Malaria Elimination Strategic Plan 2017-2021. http://www.makingmalariahistory.org/wp-content/ uploads/2017/06/NMESP_2017-21_email-version.pdf. Accessed December 23, 2019.

21. Rodríguez JC, Uribe GÁ, Araújo RM, Narváez PC, Valencia SH. Epidemiology and control of malaria in Colombia. Mem Inst Oswaldo Cruz. 2011;106 Suppl 1:114-122. doi:10.1590/s007402762011000900015.

22. Nawa M, Hangoma P, Morse AP, Michelo C. Investigating the upsurge of malaria prevalence in Zambia between 2010 and 2015: a decomposition of determinants. Malar J. 2019;18(1):61. doi:10.1186/s12936-019-2698-x.

23. Masaninga F, Mukumbuta N, Ndhlovu K, et al. Insecticide-treated nets mass distribution campaign: benefits and lessons in Zambia. 
Malar J. 2018;17(1):173. doi:10.1186/s12936-018-2314-5.

24. Chanda E, Mukonka VM, Kamuliwo M, Macdonald MB, Haque $U$. Operational scale entomological intervention for malaria control: strategies, achievements and challenges in Zambia. Malar J. 2013;12:10. doi:10.1186/1475-2875-12-10

25. Hast MA, Chaponda M, Muleba $M$, et al. The impact of three years of targeted IRS with pirimiphos-methyl on malaria parasite prevalence in a high-transmission area of northern Zambia. Am J Epidemiol. 2019. doi:10.1093/aje/kwz107.

26. Ministry of Health M, Central Statistics Office (CSO), PATH Malaria Control and Evaluation Partnership in Africa (MACEPA), the United States President's Malaria Initiative (PMI), the World Bank, UNICEF, the World Health Organization, (WHO). Malaria Indicator Survey 2018. Lusaka, Zambia: PATH; 2019.

27. Ministry of Health M, Central Statistics Office (CSO), PATH Malaria Control and Evaluation Partnership in Africa (MACEPA), the United States President's Malaria Initiative (PMI), the World Bank, UNICEF, the World Health Organization, (WHO). Malaria Indicator Survey. Lusaka: Ministry of Health, 2015.

28. Central Statistical Office, Ministry of Health, ICF International. Zambia Demographic and Health Survey 2013-14. Rockville, Maryland, USA: Central Statistical Office, Ministry of Health, ICF International; 2014.

29. Wiedinmyer C, Dickinson K, Piedrahita R, et al. Rural-urban differences in cooking practices and exposures in Northern Ghana. Environ Res Lett. 2017;12(6):065009. doi:10.1088/17489326/aa7036.

30. Janko MM, Irish SR, Reich BJ, et al. The links between agriculture, Anopheles mosquitoes, and malaria risk in children younger than 5 years in the Democratic Republic of the Congo: a populationbased, cross-sectional, spatial study. Lancet Planet Health. 2018;2(2):e74-e82. doi:10.1016/s2542-5196(18)30009-3. 